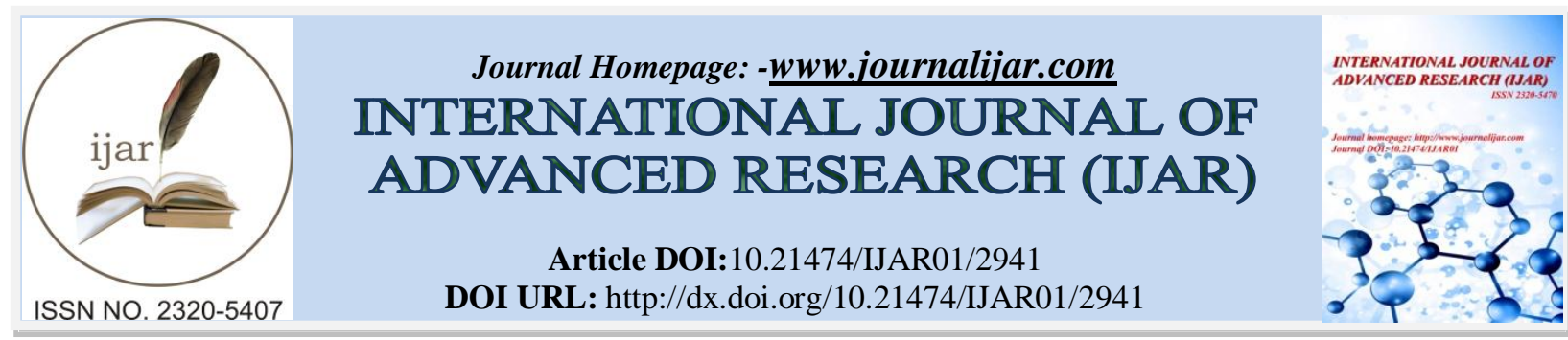

RESEARCH ARTICLE

\title{
EFFECT OF POMEGRANATE JUICE AND PEEL ON ANTIOXIDANT ENZYMES AND LIPID PROFILE IN CARBON TETRACHLORIDE-INDUCED HYPERLIPIDEMIC RATS.
}

\author{
Doaa M. Genena ${ }^{1}$ and Neveen F. Agamy ${ }^{2}$. \\ 1. Fellow of Nutrition, Medical Research Institute - University of Alexandria \\ 2. Assistant Professor of food analysis, High Institute of Public Health- University of Alexandria
}

\section{Manuscript Info}

Manuscript History

Received: 25 November 2016

Final Accepted: 27 December 2016

Published: January 2017

Key words:

Pomegranate, polyphenols, antioxidants, antioxidants enzymes, hyperlipidemia , lipid profile.

\begin{abstract}
Lipid peroxidation is a crucial step in the pathogenesis of free radicalrelated disease states, including glomerulonephritis, rheumatoid arthritis, gastrointestinal and cardiovascular diseases. Antioxidants play a significant role in protecting living organism from the toxic effect of various chemicals by preventing free radical formation. Pomegranate is a good source of polyphenols and other antioxidants. The purpose of the present study is to evaluate the effect of pomegranates juice and peel administration on antioxidant enzymes activities and lipid profile in carbon tetrachloride-induced hyperlipidemic rats. Hyperlipidemic rats were treated with pomegranates juice and peel for 8 weeks. Results showed that all hyperlipidemic rats administrated juice and peel had significant decrease in TBARS concentration and increase in GSH, GPx, GST, CAT and SOD in plasma compared to CCl4 group. Lipid profile parameters (except HDL-C) decreased significantly with juice and peel administration compared to $\mathrm{CCl} 4$ group. In conclusion, consumption of pomegranate juice and peel showed significant improvement of lipid parameters and antioxidant enzyme activities in hyperlipidemic rates suggesting therapeutic potential of using pomegranate as a medicinal plant for managing hyperlipidemia and modifying the risk of CVD.

Copy Right, IJAR, 2016,. All rights reserved.
\end{abstract}

\section{Introduction: -}

Human are continuously exposed to different kindsof chemicals such as food additives, industrialchemicals, pesticides and other undesirablecontaminants in the air, food and soil(Stavric, 1994).These substancesmostly induce a freeradical-mediated lipid peroxidation leading todisruption of biomembranes and cellular dysfunction. Lipid peroxidation is thought to play an important role in the pathogenesis of free radical-related disease states, including glomerulonephritis, rheumatoid arthritis, gastrointestinal and cardiovascular diseases(Cho et al., 2003). Oxidative stress has been linked to an altered lipid profile and endothelial damage which is a crucial event in the most common pathological processes underlying cardiovascular diseases (CVD)(Halperin et al., 2006). Additionally, the wellknown side effects of the current synthetic lipid-lowering drugs have increased the need to move toward alternative treatment for the prevention of hyperlipidemia including medicinal plants and natural antioxidants(Pahan, 2006).

Antioxidants play a significant role in protecting living organism from the toxic effect of various chemicals by preventing free radical formation(Sheweita et al., 2001). Studies have demonstrated that there are approximately 5000 known plant phenolics and many of them have antioxidant activity(Pace et al., 2006). During last years, the 
interest in the antioxidant properties of the phenolic compounds in vegetables and fruits among agricultural and food scientists, nutritionists, food industry professionals and consumers had increased, derived from their strong activityand low toxicity compared with those of synthetic phenolic antioxidants, such as butylated hydroxytoluene(Dolatabadi et al., 2010).

Punica granatum L., commonly called pomegranate has an ancient history; sculptured representations of the fruit are found on the ancient monuments of Egypt and the Assyrian ruins. The tree is native to the region of Persia and the Himalayan ranges of India and has been cultivated in Iran, Afghanistan, Pakistan, North India, Armenia, Azerbaijan, Georgia, and the Mediterranean region for several millennia(Jurenka et al., 2008). Pomegranate has been used in various regions and folk or traditional medicine because of its enormous compounds with lots of activities and without toxicity(Lansky et al., 2007).Pomegranate juice is an affluent source of polyphenols with high antioxidative potential. Moreover, its antihypertensive, and anti-inflammatory effects have been shown in limited studies in human and murine models. Pomegranate juice showed an antioxidant activity three times higher than red wine and a green tea infusion(Gil et al., 2000).Pomegranate juice also displayed potent antiatherogenic action in atherosclerotic mice and humans(Aviram et al., 2000).

Carbon tetrachloride $\left(\mathrm{CCl}_{4}\right)$, a well-known model agent for producing chemical hepatic injury, requires biotransformation by hepatic microsomal cytochrome P450 to produce toxic metabolites,namely trichloromethyl free radicals $\left(\mathrm{CCl}_{3} \bullet\right)$ andsubsequent derivative $\left(\mathrm{Cl}_{3} \mathrm{COO} \bullet\right)($ Brautbar et al., 2002). These radicals may interact with membrane lipids leading to peroxidation(Aamir et al., 2011). CCl4 causes an imbalance between the synthesis and degradation of lipids(Boll et al., 2001). In view of this, this study was carried out to evaluate the effect of pomegranate juice and peel administration on antioxidant enzymes activities and lipid profile in carbon tetrachloride-induced hyperlipidemic rats.

\section{Materials and Methods:-}

The component used in the preparation of products and standard diet were purchased from local markets in Alexandria, Egypt.CCL 4 was purchased from Merck; Darmstadt. The dose of $\mathrm{CCL}_{4}$ used was $1 \mathrm{ml} / \mathrm{kg}$ BW twice a week(Zuinen et al., 2007).Commercial kits were obtained from Biosystems S.A. (Spain), Diamond (Germany) and Randox (United Kingdom).Methanol, Folin- Ciocalteu (Prolabo) reagent, Sodium Carbonate, Gallic Acid, Rutin, $\mathrm{AlCl}_{3}$, DPPH reagent were obtained from Central laboratory unit for advanced environmental and biological analyses, High institute of public health, Alexandria University. The studywas approved by the ethical committee of the High Institute of Public Health, Alexandria University.

\section{Preparation of Pomegranate juice:-}

Pomegranate was purchased from local markets in Alexandria, Egypt. The fresh pomegranate fruits, free of blemishes or obvious defects were washed and cut into pieces, the rind was removed, and seeds were separated. Juice was obtained using a commercial blender (Braun blender, Germany), filtrated with a Buchner funnel and immediately diluted with distal water to volume of $1: 3$ and stored at $20^{\circ} \mathrm{C}$. The chosen dose of Pomegranate juice for the experiment was $5 \mathrm{ml} / \mathrm{Kg} \mathrm{BW(Osman} \mathrm{et} \mathrm{al.,} \mathrm{2011).}$

\section{Preparation of pomegranate peel powder:-}

The pomegranate peel was collected, washed, cut into small pieces and dried in air then in an oven at $50^{\circ} \mathrm{C}$ till complete dryness. The dried peel was grounded to fine powder in a mechanical blender and stored at $3-4^{\circ} \mathrm{C}$ until used. For the experimental protocol, 5\% of pomegranate peel powder were added to the standard diet(Abdou et al., 2012).

\section{Experimental animals and protocol:-}

Fifty male rats about 130-150 gm were obtained from the Medical Research Institute, Alexandria University, Alexandria, Egypt. The animals were housed in cages under standard condition of illumination with a 12-h lightdark cycle at $25 \pm 1^{\circ} \mathrm{C}$ (Childs et al., 2002). Animals were housed 5 per cage and fed on standard rodent pellet diet (Gold Mohar, Lipton - India, Ltd), and tap water ad libitum for two weeks before the beginning of the experiment for rehabilitation. Diets were presented to rats in special non- scattering feeding cups to avoid loss of food and contamination. Every day the animals were observed for the external appearance, shape, color, distribution of hair and physical activity. The animals were then divided randomly into the following five groups:

Group (1): Ten rats served as control group given the standard diet for 8 weeks. 
Group (2):Ten rats were given the standard diet and treated with $\mathrm{CCL}_{4}$ alone $(1 \mathrm{ml} / \mathrm{Kg} \mathrm{BW})$ twice a week for 8 weeks.

Group(3):Ten rats were given the standard diet and treated with combination of $\mathrm{CCL}_{4}(1 \mathrm{ml} / \mathrm{kg} \mathrm{BW})$ and pomegranate juice $(5 \mathrm{ml} / \mathrm{Kg} \mathrm{BW})$ for 8 weeks.

Group (4): Ten rats were treated with combination of $\mathrm{CCL}_{4}(1 \mathrm{ml} / \mathrm{Kg} \mathrm{BW})$ andpomegranate peel alone added to standard diet by $5 \%$ for 8 weeks.

Group (5): Ten rats were treated with combination of $\mathrm{CCL}_{4}(1 \mathrm{ml} / \mathrm{KgBW})$, pomegranate juice $(5 \mathrm{~m} 1 / \mathrm{Kg} \mathrm{BW})$ andpomegranate peel by $5 \%$ for 8 weeks.

\section{Measured parameters and techniques:}

At the end of the experiment, rats were fasted overnight and anesthetized with chloroform. The blood samples were collected in tubes with heparin (anti-coagulant). The heparinated blood samples were placed immediately in ice. Plasma samples were obtained by centrifugation at $860 \mathrm{xg}$ for $20 \mathrm{~min}$, and were stored at $-20^{\circ} \mathrm{C}$ until analyses.Liver was immediately removed at the end of the experiment; weighed and washed using chilled saline solution. Tissues were minced and homogenized ( $10 \% \mathrm{w} / \mathrm{v})$ in ice-cold sodium potassium phosphate buffer $(0.01 \mathrm{M}, \mathrm{pH} 7.4)$ containing $1.15 \% \mathrm{KCl}$ in a Potter-Elvehjem typehomogenizer. The homogenate was centrifuged at $10,000 \times \mathrm{g}$ for 20 $\min$ at $4^{\circ} \mathrm{C}$. The resultant supernatant of the organs was used for the measurement of different enzyme activities.

\section{Estimation of antioxidant enzymes in plasma and liver:-}

The activity of Glutathione S-transferase (GST; EC 2.5.1.18), Glutathione reductase (GSH) Glutathione peroxidase (GPx; EC. 1.1.1.9) was determined by the methods of Habig et al.,(1974), Beutler et al., (1963), andChiu et al., (1976) respectively. Catalase (CAT; EC 1.11.1.6) activity was assayed using the Luck method involving the decomposition of hydrogen peroxide (Luck, 1971). Superoxide dismutase (SOD; EC 1.15.1.1) activity was measured according to Misra and Fridovich (1972).Plasma thiobarbituric acid-reactive substances (TBARS) were measured by the method of Tappel and Zalkin (1959).

\section{Lipid profile:-}

Plasma concentrations of total lipids, total cholesterol (TC) and triglycerides (TG) were determined per the methods of Frings et al., (1972), Watson (1960), andFossati et al., (1982), respectively. High-density lipoprotein (HDL-C) was measured according to the methods of Warnicket al., (1983). Low-density lipoprotein (LDL-C) was determined by the calculation (cholesterol-(TG/5+HDL-C). Very low-density lipoprotein (VLDL-C) was calculated by dividing the values of TG by factor of 5 .

\section{Statistical analysis:-}

Data were analyzed using SPSS software package version 20 (SPSS, Chicago, IL, USA). P value $(<0.05)$ was considered significant. The data wereassessed for normality using Kolmogorov-Smirnov test. The data were normally distributed and presented as mean \pm standard deviation. One way ANOVA test was used to compare the mean for different measures among the different experimental groups, followed by post-hoc pairwise comparison with adjustment of $\mathrm{P}$ value using Bonferroni correction.

\section{Results and Discussion:-}

Data in Table 1 shows the effects of pomegranate juice and peel on antioxidant enzymes activities in CCl4-induced hyperlipidemic rats. CCl4 significantly $(\mathrm{p}<0.05)$ increased TBARS and decreased GSH levels as well as GPx, GST, CAT and SOD activities in plasma of the rat group treated only with CCl4 as compared to control group. In other words, CCl4 induced oxidative stress in plasma as manifested by the alterations observed in antioxidant defense systems both enzymatic and non-enzymatic. Lipid peroxidation is one of the principal causes of CCl4 toxic effect and is mediated by the free radicals' derivatives of CCl4. Our results are in consistence with the results of Shih et al. (2005) who confirmed that the hepatic activity of superoxide dismutase was markedly decreased by $\mathrm{CCl} 4$ treatment. Also,Comporti (1985) indicated a substantial increase in ROS, MDA levels and depletion of GSH levels in CCl4 intoxicated rats.

On the other hand, our study demonstrated that treatment of hyperlipidemic rats with combination of CCL4, pomegranate juice and peel caused significant $(\mathrm{p}<0.05)$ decrease in TBARS concentration and increase in GSH, GPx, GST, CAT and SOD activities. In other words, pomegranate juice and peel reduced the toxic effects of CCl4 (Table1). The significant elevation in GSH, GST, SOD, GPx and catalase of plasma indicates the protection offered 
by juice and peel against CCl4 induced toxicity. It is known that some flavonoids are able to reduce xenobiotic induced toxicity in animals and counteract the damaging effects of oxidative stress, cooperating with natural systems like glutathione and other endogenous protective enzymes(Kadarian et al., 2002). These results are in agreement with Mohieldin et al. (2011) whorevealedthattreating rats with carbon tetrachloride andpomegranate peel ethanolic extract had significantly decrease the GST, catalase and SOD activity, and significantly increase the GST, catalase and SOD activity when compared with CCl4-treated group during the hepatoprotective and curative periods.Our findings are also confirmed by the findings of Aviram et al., (2004)who reported that total antioxidant status in serum of patients with carotid artery stenosis was substantially increased, by $130 \%$ after 12 months of juice consumption. The effect of juice may be related to its potent tannins and anthocyanins which scavenge wide spectrum of free radicals.(Gil et al., 2000), (Aviram et al., 2000).

Pomegranate peel administration showed insignificant higher levels of plasma GSH, GPx, GST, CAT, and SOD when compared to juice, which is may be due to the slightly higher content of polyphenols in peel than in juice. Aviram et al., (2000) found that the inner and outer peels contain 20-30 fold more polyphenols than do the aqueous fractions of the seeds and Juice (566 and $739 \mu \mathrm{mol}$ polyphenols/mg compared with 22 and $25 \mu \mathrm{mol}$ polyphenols/mg, respectively).

The decrease of TBARS in plasma of the hyperlipidemic rat groups treated with juice and peel (Table 1) agrees with the results ofNaveena et al., (2008)who reported that the free radical scavenging activity of pomegranate peel phenolics involves electron donation to free radicals that converts them to relatively more stable compounds. Several studies have confirmed the antioxidant and free radical scavenging activity of phenolic compounds derived from pomegranates, the antioxidant activity of plants extracts depends on the concentration of phenolic compounds, and the antioxidant power of pomegranate peel extract has been found to linearly increase with the concentration of peel phenolics up to the level of $400 \mu \mathrm{g} / \mathrm{g}$ (Sönmez et al., 2005), (Rosenblat et al., 2006).

Data listed in Table 2 shows the effect of pomegranate juice and peel on lipid profile of CCl4-induced hyperlipidemic rats. Treatment of rats with $\mathrm{CCl} 4$ caused a significant increase $(\mathrm{p}<0.05)$ in plasma TG, TC, LDL-C and VLDL-C, while HDL-C was significantly decreased $(\mathrm{p}<0.05)$ compared to control group. These findings are in agreement with the results of Uličná1 et al. (2003) who reported that the long-term intraperitoneally administration of CCl4 to experimental animals induced, as expected, pathological changes in the liver. $\mathrm{CCl} 4$ treatment of rats also caused a severe increase of hepatic triacylglycerol, total cholesterol and Malondialdehyde. The highly reactive free radical (trichloromethyl, $\mathrm{CCl}^{\circ}$-) in the presence of oxygen leads to auto-oxidation of fatty acids and causes functional and morphological changes in the cell membrane. Scavenging of free radicals is one of the major antioxidation mechanisms to inhibit the chain reaction of lipid peroxidation. ROS are highly reactive and can react with many intracellular molecules, mainly unsaturated fatty acids (phospholipids, glycolipids, glycerides and sterols) and transmembrane proteins with oxidizable amino acids. The oxidation of these molecules causes the increase in the cellular membrane permeability. ROS can attack the unsaturated bonds of the membrane lipids in an autocatalytic process, with the genesis of peroxides, alcohol and lipidic aldehydes as by-products of the reaction. Thus, the increase of free radicals in cells can induce the lipid peroxidation by oxidative breakdown of polyunsaturated fatty acids in membranes of cells(Henke et al., 2005).

Meanwhile, our study reported that treatment of hyperlipidemic rats with pomegranate juice caused a significant decrease $(\mathrm{p}<0.05)$ in plasma lipids except HDL-C, which was significantly increased $(\mathrm{p}<0.05)$ compared to control group.These results are in agreement with Esmaillzadeh et al., (2006) who found that pomegranate juice significantly reduced TC, LDL-C, the ratio of LDL-C/HDL-C, and the ratio of TC to HDL-C. Another study on mice fed pomegranate juice, plasma lipid peroxidation was markedly lower, and this effect was dependent on concentration(Aviram et al., 2000). Furthermore, Aviram et al., (2004) showed that pomegranate juice consumption for 3 years on patients with carotid artery stenosis reduces common carotid intima-media thickness, blood pressure and LDL-C oxidation. Khoo et al., (1990) reported that LDL-C aggregation was inhibited in vitro by pomegranate juice; this inhibition may be related to hydrophobic interactions between constituents of pomegranate juice and the lipoprotein.Pomegranate juice was indeed shown to possess impressive antioxidative properties due to its polyphenolics, tannins and anthocyanins(Gil et al., 2000). Additionally, phenolic compounds derived from pomegranate, vitamins $\mathrm{C}$ and $\mathrm{E}$, melatonin and lycopene have been used as antioxidant agents to prevent various lipid-peroxidation-induced damages in different organs(Sönmez et al., 2005), (Rosenblat et al., 2006), (Sönmez et al., 2007),(Türk et al., 2007). Polyphenolic flavonoids not only affect cellular oxygenases but also cause 
conformational changes in plasma membrane constituents, such as cellular receptors for lipoproteins(Aviram et al., 2000).

The decrease in plasma lipid profile of hyperlipidemic rats treated with peel which is showed in the present study is in agreement with Hossin(2009)who evaluated the pomegranate peel powder as a dietary fiber source for the treatment of hypercholesterolemia and atherosclerosis and found that dietary supplementation with peel powder at a concentration of 5,10 and $15 \mathrm{~g} / 100 \mathrm{~g}$ for a period of four weeks significantly reduced serum TC, TG, LDL-C, VLDL-C and lipid peroxidation levels in Hypercholesterolemic rats. Results of the present study confirm thesefindings(Table2).He alsoreported that all Hypercholesterolemic groups administered with different level of pomegranate peel extract $(1,2$ and $3 \%$ ) had significant decrease in serum TC, LDL-C-, VLDL-C, lipid peroxidation and atherogenic index and triglycerides comparing with control positive. Additionally, Ibrahim (2010)noticed that feeding the rats on standard diet containing 400 or $800 \mathrm{mg} / \mathrm{Kg} \mathrm{BW}$ pomegranate peel extract for 4 weeks obviously decreased $(\mathrm{P}<0.05)$ levels of TC, TG and TL.Pomegranate peel polyphenolic extract is effective in lowering serum and hepatic lipids(Cheng et al., 2005).

In the current study pomegranate peel was shown to be more influential in lowering level of lipid profile than juice, which is consistent with the findings of Aviram et al., (2000) who compared between the juice and the peel in terms of total polyphenol content. The researchers analyzed the antioxidant properties of pomegranate constituents other than the juice; they prepared aqueous solutions of the inner and outer peels and the crushed seeds and found that the aqueous extracts of the inner and outer peels were more powerful antioxidants than the juice, suggesting that the inner and outer peels may contain more potent antioxidant polyphenols. The aqueous extract obtained from the crushed seeds was found to be a weak antioxidant against LDL-Coxidation.

Based on the previous results, the authors concluded that the consumption of pomegranate juice and peel caused significant improvement of lipid parameters and antioxidant enzyme activities in hyperlipidemic rats suggesting therapeutic potential of using pomegranate as a medicinal plant for managing hyperlipidemia and modifying the risk of CVD.

Table 1:- Effect of pomegranate juice and peel on antioxidant enzymes activities in CCl4-induced hyperlipidemic rats.

\begin{tabular}{|c|c|c|c|c|c|}
\hline \multirow[t]{2}{*}{ Parameter } & \multicolumn{5}{|c|}{ Experimental groups } \\
\hline & Control & $\mathrm{CCL}_{4}$ & $\mathrm{CCL}_{4}+\mathbf{J}^{*}$ & $\mathrm{CCL}_{4}+\mathrm{P}^{*}$ & $\mathrm{CCL}_{4}+\mathrm{J}^{*}+\mathrm{P} *$ \\
\hline \begin{tabular}{|l} 
TBARS \\
$(\mathrm{nmol} / \mathrm{ml})$ \\
\end{tabular} & $0.54 \pm 0.01^{\mathrm{d}}$ & $0.97 \pm 0.03^{\mathrm{a}}$ & $0.71 \pm 0.01^{b}$ & $0.67 \pm 0.02^{\mathrm{b}}$ & $0.63 \pm 0.01^{\mathrm{c}}$ \\
\hline $\begin{array}{l}\text { GSH } \\
(\mathrm{U} / \mathrm{ml})\end{array}$ & $0.549 \pm 0.05^{b}$ & $0.250 \pm 0.02^{\mathrm{e}}$ & $0.406 \pm 0.03^{\mathrm{d}}$ & $0.457 \pm 0.03^{\mathrm{cd}}$ & $0.498 \pm 0.03^{\mathrm{cb}}$ \\
\hline \begin{tabular}{|l} 
GPx \\
$(\mathrm{U} / \mathrm{ml})$ \\
\end{tabular} & $16.63 \pm 1.09^{b}$ & $7.39 \pm 0.60^{d}$ & $12.16 \pm 0.65^{\mathrm{c}}$ & $13.92 \pm 1.17^{b c}$ & $14.98 \pm 1.18^{\mathrm{bc}}$ \\
\hline $\begin{array}{l}\text { GST } \\
(\mu \mathrm{mol} / \mathrm{hr} . / \mathrm{ml})\end{array}$ & $1.03 \pm 0.02^{b}$ & $0.49 \pm 0.03^{\mathrm{e}}$ & $0.82 \pm 0.02^{\mathrm{d}}$ & $0.86 \pm 0.02^{\text {cd }}$ & $0.92 \pm 0.02^{c}$ \\
\hline $\begin{array}{l}\text { CAT } \\
(\mathbf{u} / \mathbf{m i n} / \mathrm{ml})\end{array}$ & $51.83 \pm 3.90^{b}$ & $22.71 \pm 0.99^{d}$ & $40.58 \pm 3.63^{c}$ & $43.75 \pm 4.02^{b c}$ & $45.63 \pm 3.66^{b c}$ \\
\hline \begin{tabular}{|l} 
SOD \\
$(\mathrm{U} / \mathrm{ml})$
\end{tabular} & $2.73 \pm 0.02^{b}$ & $1.40 \pm 0.10^{\mathrm{d}}$ & $2.08 \pm 0.03^{\mathrm{c}}$ & $2.39 \pm 0.03^{\mathrm{bc}}$ & $2.55 \pm 0.10^{b}$ \\
\hline
\end{tabular}

${ }^{*} \mathrm{~J}$ : Pomegranate juice, ${ }^{*} \mathrm{P}$ : Pomegranate peel.

Values are expressed as means $\pm \mathrm{SE} ; \mathrm{n}=10$ for each treatment group. Mean values within a row not sharing a common superscript letter (a, b, c, d, e, f) were significantly different, $\mathrm{p}<0.05$.

Table 2:-Effect of pomegranate juice and peel on lipid profile in CCl4-induced hyperlipidemic rats.

\begin{tabular}{|c|c|c|c|c|c|}
\hline \multirow[b]{2}{*}{ Parameter } & \multicolumn{5}{|c|}{ Experimental groups } \\
\hline & Control & CCL4 & CCL4+J* & CCL4+P* & CCL4+J+P \\
\hline TL(mg/dl) & $508.75 \pm 11.31^{\mathrm{c}}$ & $677.88 \pm 10.00^{\mathrm{a}}$ & $574.98 \pm 11.91^{\mathrm{b}}$ & $557.94 \pm 6.32^{b}$ & $555.13 \pm 24.43^{\mathrm{b}}$ \\
\hline TC(mg/dl) & $147.72 \pm 5.45^{\mathrm{d}}$ & $198.76 \pm 4.40^{\mathrm{a}}$ & $181.93 \pm 7.86^{\mathrm{ab}}$ & $168.67 \pm 6.47^{\mathrm{bc}}$ & $160.35 \pm 6.31^{\mathrm{cd}}$ \\
\hline TG(mg/dl) & $123.00 \pm 5.43^{\mathrm{b}}$ & $159.30 \pm 4.24^{\mathrm{a}}$ & $149.13 \pm 10.79^{a}$ & $146.15 \pm 12.27^{\mathrm{a}}$ & $138.87 \pm 8.11^{\mathrm{ab}}$ \\
\hline
\end{tabular}




\begin{tabular}{|l|l|l|l|l|l|}
\hline HDL-C(mg/dl) & $54.48 \pm 2.63^{\mathrm{b}}$ & $36.21 \pm 2.87^{\mathrm{e}}$ & $40.31 \pm 1.62^{\text {ed }}$ & $45.87 \pm 2.57^{\text {cd }}$ & $48.06 \pm 2.98^{\mathrm{bc}}$ \\
\hline LDL-C(mg/dl) & $68.64 \pm 1.73^{\mathrm{c}}$ & $130.69 \pm 0.68^{\mathrm{a}}$ & $111.79 \pm 4.08^{\mathrm{b}}$ & $93.57 \pm 1.45^{\mathrm{b}}$ & $84.42 \pm 1.71^{\mathrm{b}}$ \\
\hline VLDL-C(mg/dl) & $24.6 \pm 1.09^{\mathrm{d}}$ & $31.86 \pm 0.85^{\mathrm{a}}$ & $29.83 \pm 2.16^{\mathrm{ab}}$ & $29.23 \pm 2.45^{\mathrm{ab}}$ & $27.87 \pm 1.62^{\text {cd }}$ \\
\hline
\end{tabular}

J: Pomegranate juice, "P: Pomegranate peel.

Values are expressed as means $\pm \mathrm{SE} ; \mathrm{n}=10$ for each treatment group. Mean values within a row not sharing a common superscript letter (a, b, c, d, e, f) were significantly different, $\mathrm{p}<0.05$.

\section{References:-}

1. Aamir, S., Thippeswamy, B.S., KulKarani, V.H.and Karunakar, H. (2011):Hepatoprotective effect of euphorbia thymifolia whole plant extract on CCl4 induced hepatic damage in rats. Int J Res Ayurveda Pharm., 2(22):681-6.

2. Abdou, H.S., Salah,S.H., Boolesand, F.H. and Abdel, RahimE.A. (2012): Effect of pomegranate pretreatment on genotoxicity and hepatotoxicity induced by carbon tetrachloride $\left(\mathrm{CCl}_{4}\right)$ in male rats. J. Medicinal Plants Research. 6(17):3370- 3380.

3. Aviram, M., Dornfeld, L., Rosenblat, M., Volkova, N., Kaplan, M., Coleman, R., Hayek, T., Presser, D. and Fuhrman, B. (2000): Pomegranate juice consumption reduces oxidative stress, atherogenic modifications to LDL and platelet aggregation: studies in humans and in atherosclerotic apolipoprotein E-deficient mice. Am. J. Clin. Nutr., 71(5):1062-76.

4. Aviram, M., Rosenblat, M., Gaitini, D., Nitecki, S., Hoffman, A., Dornfeld, L., Volkova, N., Presser, D., Attias, J., Liker, H. and Hayek, T. (2004): Pomegranate juice consumption for 3 years by patients with carotid artery stenosis reduces common carotid intima-media thickness, blood pressure and LDLoxidation. Clin Nutr., 23(3):423-33.

5. Beutler, E., Duron, O. and Kelly, B.M. (1963). An improved method for the detection of blood glutathione. J. Lab. Clin. Med., 61:882-88.

6. Boll, M., Weber, L.W., Becker, E. and Stampfl, A. (2001): Pathogenesis of carbon tetrachloride-induced hepatocyte injury bioactivation of CCI4 by cytochrome P450 and effects on lipid homeostasis. Z Naturforsch C., 56(1-2):111-21.

7. Brautbar, N., and Williams, J. (2002):Industrial solvents and liver toxicity: Risk assessment, risk factors and mechanisms. Int J Hyg Environ Heal., 205(6):479-91.

8. Cheng, S., Guo, C.J., Yang, J., Wel, J.Y., Li,Y.F. and Xu, J. (2005):Experimental study on hypolipidemic effect of polyphenolic extract from pomegranate peel. J Prev Med Chinese People,s Lib Army.

9. Childs, A.C., Phaneuf, S.L., Dirks, A.J., Phillips, T. and Leeuwenburgh, C. (2002): Doxorubicin treatment in vivo causes cytochrome $\mathrm{C}$ release and cardiomyocyte apoptosis, as well as increased mitochondrial efficiency, superoxide dismutase activity, and Bcl-2:Bax ratio. Cancer Res., 62(16):4592-8.

10. Chiu, D.T., Stults, F.H. and Tappel, A. (1976): Purification and properties of rat lung soluble glutathione peroxidase. Biochim Biophys Acta., 445(3):558-66.

11. Cho, E.J., Yokozawa, T., Rhyu, D.Y., Kim, H.Y., Shibahara, N.and Park, J.C. (2003): The inhibitory effects of 12 medicinal plants and their component compounds on lipid peroxidation. Am J Chin Med., 31(6):907-17.

12. Comporti, M, (1985):Lipid peroxidation and cellular damage in toxic liver injury. Lab Invest., 53(6):599-623.

13. Dolatabadi, J.E. and Kashanian, S. (2010): A review on DNA interaction with synthetic phenolic food additives. Food Research International, 43;1223-30.

14. Esmaillzadeh, A., Tahbaz, F., Gaieni, I., Alavi-Majd, H. and Azadbakht, L. (2006): Cholesterol-Lowering Effect of Concentrated Pomegranate Juice Consumption in Type II Diabetic Patients with Hyperlipidemia. Int J Vitam Nutr Res., 76(3):147-51.

15. Fossati, P. and Prencipe, L. (1982): Serum triglycerides determined colorimetrically with an enzyme that produces hydrogen peroxide. Clin Chem., 28(10):2077-80.

16. Frings, C.S., Frendley, T.W., Dunn, R.T. and Queen, C.A. (1972): Improved determination of total serum lipids by the sulfo-phospho-vanillin reaction. Clin Chem., 18(7):673-4.

17. Gil, M.I., Tomas-Barberan, F.A., Hess-Pierce, B., Holcroft, D.M. and Kader, A.A. (2000): Antioxidant activity of pomegranate juice and its relationship with phenolic composition and processing. J Agric Food Chem., 48(10):4581-9.

18. Habig, W.H., Pabst, M.J. and Jakoby, W.B. (1974): Glutathione S-transferases.The first enzymatic step in 
mercapturic acid formation. J Biol Chem., 25;249(22):7130-9.

19. Halperin, R.O., Sesso, H.D., Ma, J., Buring, J.E., Stampfer, M.J. and Gaziano, J.M. (2006):Dyslipidemia and the risk of incident hypertension in men. Hypertension. 47(1):45-50.

20. Henkel, R. (2005): The impact of oxidants on sperm function. Andrologia. 37(6):205-6.

21. Hossin,F.L.(2009): Effect of pomegranate (Punica granatum) peels and it's extract on obese hypercholesterolemic rats. Pakistan J Nutr., 1;8(8):1251-7.

22. Ibrahium, M.I. (2010): Efficiency of pomegranate peel extract as antimicrobial, antioxidant and protective agents. World J Agric Sci., 6(4):338-44.

23. Jurenka, J.S. (2008): Therapeutic applications of pomegranate (Punica granatum L.): A review. Altern Med Rev., 13(2):128-44.

24. Kadarian, C., Broussalis, A.M., MinoLopez, J., Gor-zalczany, P., Ferraro, S. and Acevedo, G. (2002): Hepatoprotective activity of Achyrocline satureioides(Lam)D.C. Pharmacol Res., 45(1):57-61.

25. Lansky, E.P. and Newman, R.A. (2007): Punica granatum (pomegranate) and its potential for prevention and treatment of inflammation and cancer. J. Ethnopharmacol., 109:177-206.

26. Luck, H.(1971):“Catalase,” In: Methods of Enzymatic Analysis, H. U. Bergmeyer, Ed., pp. 885-893, Academic Press, New York, NY, USA.

27. Misra, H.P. and Fridovich, I. (1972): The role of superoxide anion in the autoxidation of epinephrine and a simple assay for superoxide dismutase. J Biol Chem., 247(10):3170-5.

28. Naveena, B.M., Sen, A.R., Kingsly, R.P., Singh, D.B. and Kondaiah, N. (2008a): Antioxidant activity of pomegranate rind powder extract in cooked chicken patties. Int. J. Food Sci. Technol., 43:1807-12.

29. Osman, M., Ahmed, M., Mahfouz, M.U. and Elaby, S. (2011): Biochemical Studies on The Hepatoprotective Effects of Pomegranate and Guava Ethanol Extracts. New York Sci J., 44(33):27-39.

30. Pace, G., Lima, P., Vianello, F., Corrêa, C.R., Arnoux, R. and Campos, D.S. (2014): Polyphenols in Fruits and Vegetables and Its Effect on Human Health. Food Nutr Sci., 5(5):1065-82.

31. Pahan, K. (2006): Lipid-lowering drugs. Cell Mol Life Sci., 63(10):1165-78.

32. Rosenblat, M., Hayek, T. and Aviram, M. (2006): Anti-oxidative effects of pomegranate juice (PJ) consumption by diabetic patients on serum and on macrophages. Atherosclerosis. 187(2):363-71.

33. Sheweita, S.A., Abd El-Gabar, M. and Bastawy, M. (2001):Carbon tetrachloride-induced changes in the activity of phase II drug-metabolizing enzyme in the liver of male rats: Role of antioxidants. Toxicology. 165(2-3):217-24.

34. Shih, C.C., Wu, Y.W. and Lin, W.C. (2005): Aqueous extract of Anoectochilus formosanus attenuate hepatic fibrosis induced by carbon tetrachloride in rats. Phytomedicine.12(6-7):453-60.

35. Sonmez, M., Turk, G. and Yuce, A. (2005): The effect of ascorbic acid supplementation on sperm quality, lipid peroxidation and testosterone levels of male Wistar rats. Theriogenology. 63(7):2063-72.

36. Sonmez, M., Yuce, A. and Turk, G. (2007). The protective effects of melatonin and Vitamin E on antioxidant enzyme activities and epididymal sperm characteristics of homocysteine treated male rats. Reprod Toxicol., 23(2):226-31.

37. Stavric, B. (1994): Role of chemopreventers in human diet. Clin Biochem., 27(5):319-32.

38. Tappel, A.L. and Zalkin, H. (1959): Inhibition of lipide peroxidation in mitochondria by vitamin E. Arch Biochem Biophys., 80(2):333-6.

39. Türk, G., Ateşşahin, A., Sönmez, M., Yüce, A., Çeribaşi, A.O. (2007): Lycopene protects against cyclosporine A-induced testicular toxicity in rats. Theriogenology.67(4):778-85.

40. Ulicná, O., Greksák, M., Vancová,O., Zlatos, L., Galbavý, S. and Bozek P. (2003): Hepatoprotective effect of rooibos tea (Aspalathus linearis) on CCl4-induced liver damage in rats. Physiol Res., 52(4):461-6.

41. Warnick, G.R., Benderson, V. and Albers, N. (1983): Selected Methods. Clin. Chem. 10:91-9.

42. Watson, D. (1960): A simple method for the determination of serum cholesterol. Clin Chim Acta., 5(5):63743.

43. Zuinen, R., Yamaji, K., Aoki, M., Chikuma, T. and Hojo, H. (2007):Early induced, high-level interleukin-6 expression in the rat peritoneal cavity into which a hepatotoxicant carbon tetrachloride was administered. Toxicol Lett., 170(1):42-8. 